\title{
Austerity and Fuel Consumption in Greece: An Empirical Investigation
}

\author{
Theopisti Th. Sidiropoulou ${ }^{1}$, Ioannis A. Papanastasiou ${ }^{2}$
}

\begin{abstract}
:
Greek economic crisis in the last years and the subsequent austerity policy measures resulted to a decline in consumers' income. This paper investigates empirically the Greek consumers' reactions to income changes regarding their consumption of different types of fuels during the period 2007-2011. The empirical findings suggest that fuel consumption elasticity of income is different among different types of fuels. Furthermore the income elasticity is different among different Greek geographic regions.

More specifically, fuels with high consumption i.e. 95 RON unleaded gasoline and diesel-bio fuels are found to be income inelastic as compared to fuels with low consumption i.e. 98-100 RON unleaded gasoline and new super gasoline LRP. Furthermore, for the high consumed fuels, consumers' behavior patterns to income changes in the island are opposite to that in the rest Greek territory.
\end{abstract}

Key Words: austerity measures, Greece, fuel consumption, income elasticity, panel data

JEL codes: C33, L62

\footnotetext{
${ }^{1}$ Theopisti Th. Sidiropoulou, 14, Anaktoriou st., 54636, Thessaloniki, Greece, Tel.:0030 6944269906, t.sidiropoulou@yahoo.com

${ }^{2}$ Ioannis A. Papanastasiou, 156, Egnatia st., P.O. Box 1591, 54006, Thessaloniki, Greece, Professor at the Department of Accounting-Finance of the University of Macedonia and SEP to Hellenic Open University, Tel.: +30 2310891696, Fax: +30 2310891601, e-mail: papan@uom.gr
} 


\section{Introduction}

According to the World Fact Book (2013), the economy of the Greek state was growing fast during 2003- 2007 with a growth rate of 4.0\% per annum. The Global recession of 2008 and the Eurozone crisis of 2009 affected the Greek economy, primarily its tourism and shipping sectors (Mah et al. 2013).

The Greek government initiated a deficit-cutting policy in 2010. The fiscal policy included a drastic reduction in public spending and an increase in direct and indirect taxes (Heninz, 2011).

During the examined period (2007-2011), Greek Governments had signed four austerity packages, including The Memorandum of Economic and Financial Policies (MEFP) and The Medium-Term Fiscal Strategy (MTFS). Main feature to all these economic programs were the combination of spending cuts and tax rising. These include among others: reductions in wages and pensions, increase of the standard rate of Value Added Tax and of the petrol tax from 9\% to $15 \%$.

These policies indisputably had an impact on fuel consumption. Thus the present paper attempts to examine empirically the impact of austerity measures on the consumption of each kind of gasoline (unleaded 95 RON, super unleaded 98/100 RON, new super LRP and diesel) in all geographic departments of Greece.

It could be claimed that fuel consumption indicates a society's standard of living; the higher its level the greater the number of existing vehicles. Consequently, changes to fuel consumption attributed to austerity measures should reflect changes of people's habits and standard of living.

The impact of the crisis by imposing austerity measures appear on March 2010 when the price of gasoline increased by $15 \%$ voted and continued the same year on May $2^{\text {nd }}$, when a $10 \%$ increase in fuel excise duty imposed by the government. The price of unleaded during 2010 increased more than 50 cents a liter (an almost 50\% increase), according to the Ministry of Environment. The increase in the retail price was, namely, 51.7 cents per liter and this is mainly due to the increase in taxes (38 cents). Of course the increase in retail price of fuel was not exclusively due to the imposition of tax but also because of the rise in crude oil and the dollar exchange rate (other 10 cents).

More specifically during 2010 the excise duty rose from 41 to 67 cents per liter (up 26 cents) while VAT was risen from 15.2 to 27.5 cents (up 12.4 cents).

However, the rise of fuels' price continued and during the next year (2011) with Greece to be the European country with the most expensive price of gasoline, according to reports of the EU Commission and Eurostat. 


\section{Data Analysis and Regression Results}

The dataset consists of a panel of 51 Greek prefectures divided into 9 geographic regions covering the period 2007-2011(annual data). Data for the fuel consumption comes from the Ministry of Environment, Energy and Climate Change. The variables from each prefecture obtained from Greek statistics EL.STAT include fuel consumption (disaggregated in unleaded, super unleaded, new super and diesel-bio consumption), the number of cars, trucks, busses and motorcycles and gdp. All variables have been divided by the relevant total population numbers to provide per capita values.

Data for the number of vehicles come from the Department of Information Providers of the EL.STAT.

Diagram 1 shows the evolution of fuel per capita consumption during the five years period 2007-2011.

The following diagram shows the quantity of thousands metric tons of consumed fuel totally in Greece during the years 2007- 2011. However, the consumption it is not examined totally but it is separated into the four kinds of fuel, the three kinds of gasoline, unleaded $95 \mathrm{RON}$, unleaded $100 \mathrm{RON}$ and new super LRP, and diesel. As we can see from the diagram fuel consumption declined for every type although with a different rate. For example diesel-bio fuel per capita consumption decreased with a higher rate than that of the unleaded per capita consumption.

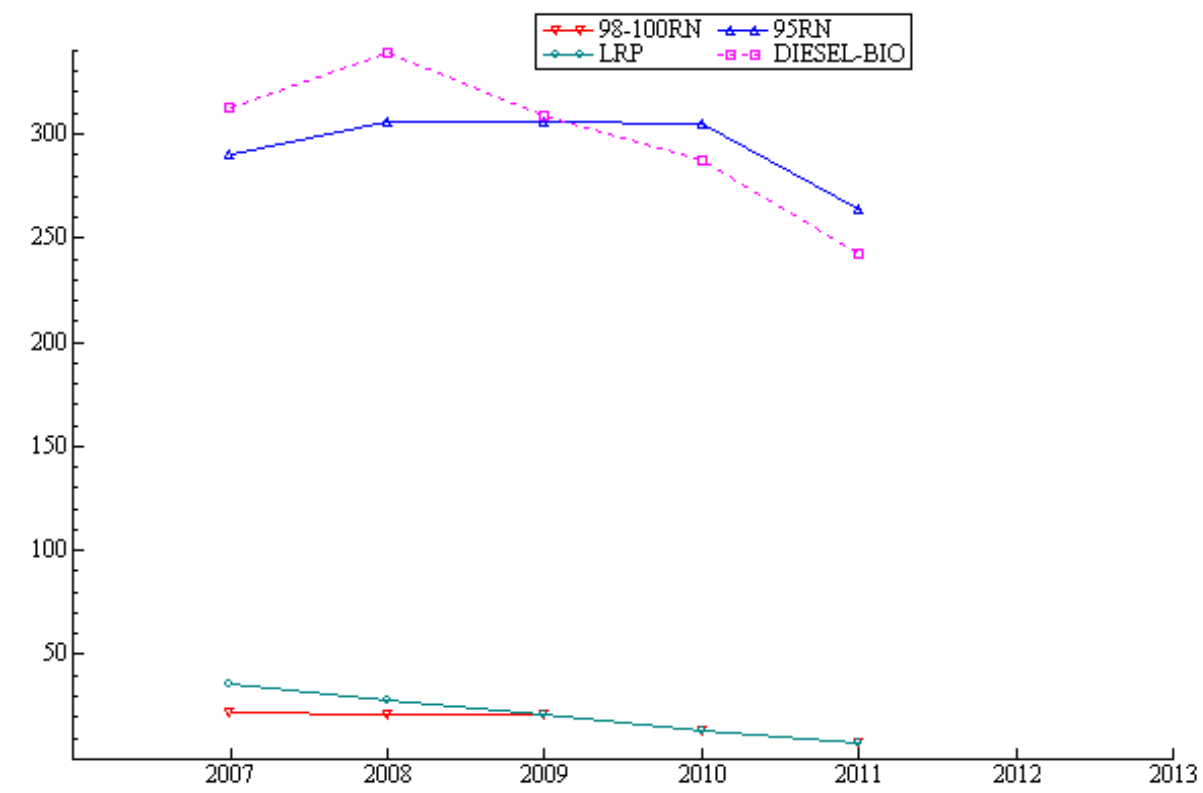

Diagram 1. Total per capita consumption of fuel in Greece 
Diagram 2 depicts the movements of the per capita gross domestic product. The diagram depicts vividly the negative effects of the austerity measures had on the income. The per capita gross domestic product had an upward trend reaching to 17000 from 16000 euro during 2007 to 2008, then declines sharply falling below 15000 euro in the four years period 2008-2011.

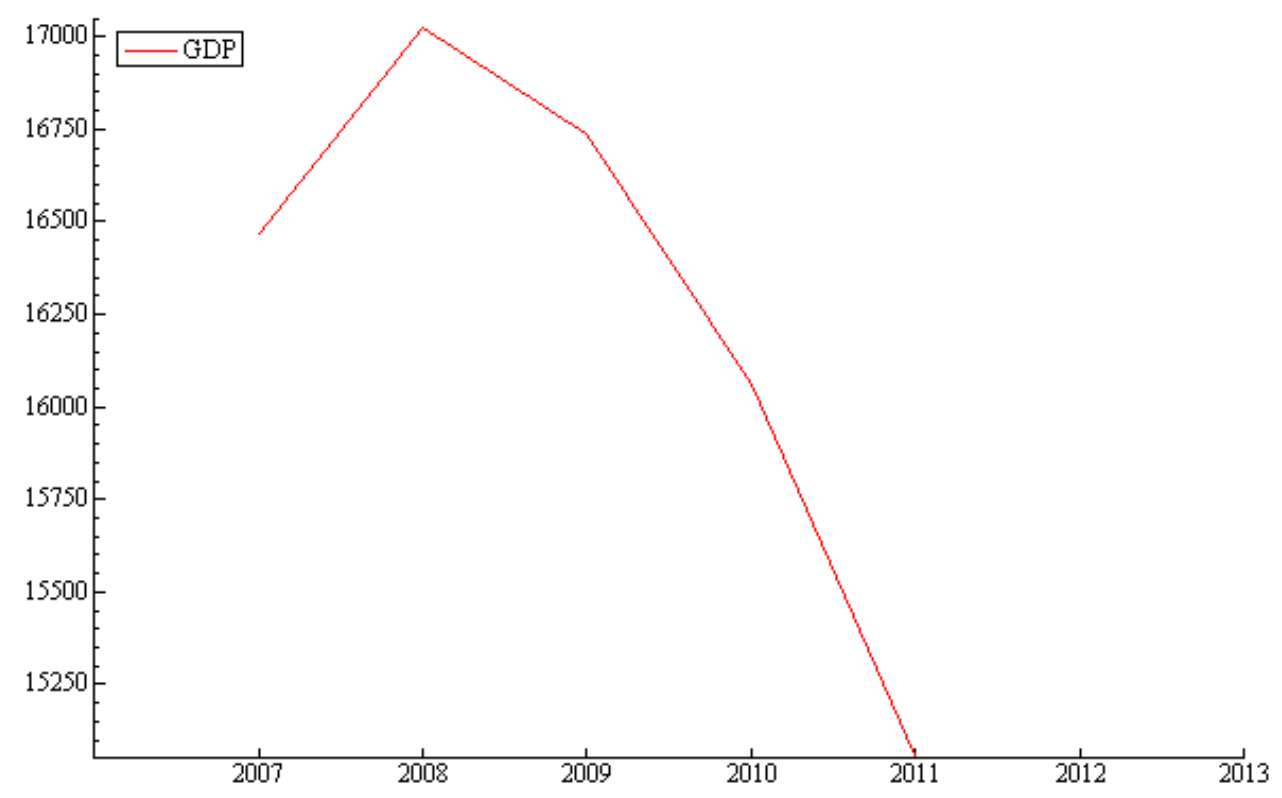

Diagram 2. Average per capita Gross domestic product at market prices

Diagram 3 presents the total number of vehicles during the period 2007-2011in Greek territory. The total number of each category of vehicles shows a partial increase during the examined period, except for buses which presents a slight decrease. Although the total number of cars has increased their growth rate and the rate of new cars entering the market decreased during 2007-2011 time period. It should be noted that similar time patterns exhibit the per capita vehicle values.

Its decline continued in 2010 and 2011 mainly due to the policy imposed by the troika and implemented by the Greek government. (Drettakis, 2011). 


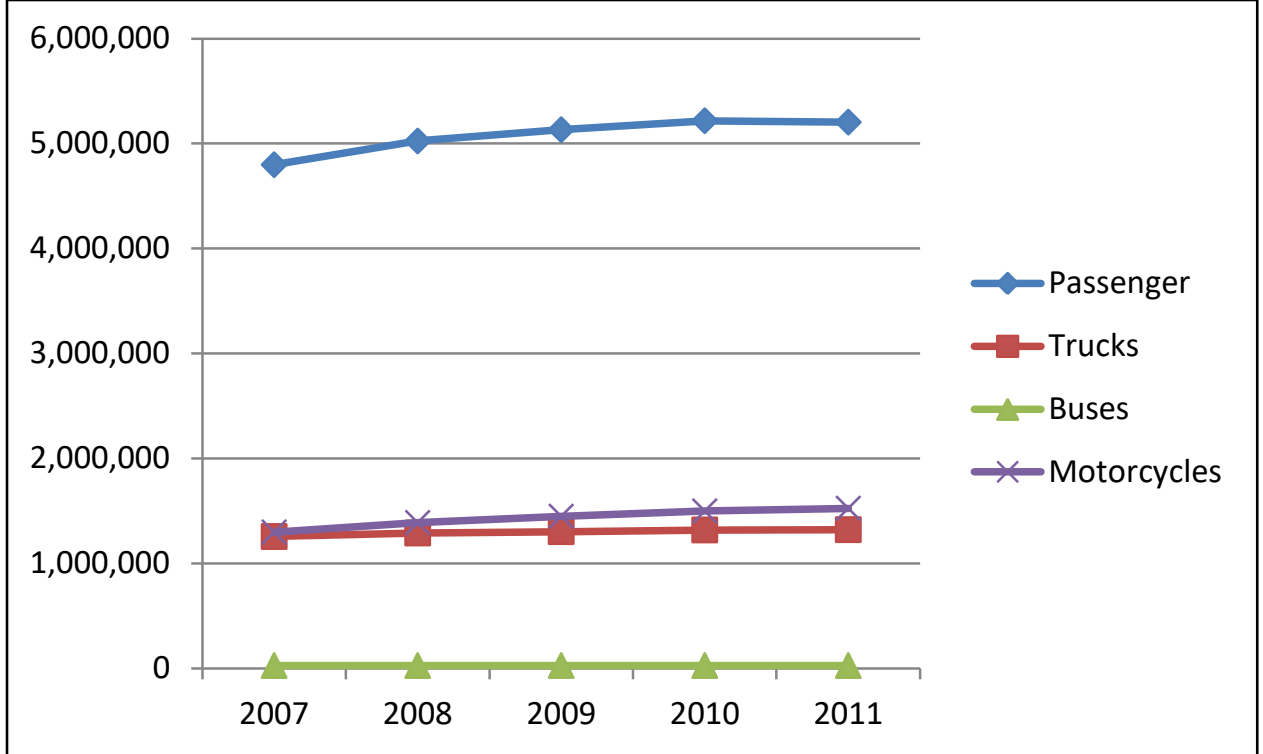

Diagram 3. Total number of vehicles in Greece

In conclusion, the combination of the rising in fuels' price, the significant reduction in income (and consumption expenditure), the increase in unemployment and the restrictive fiscal policy lead to the forced deprivation of car and vehicle in general. Ultimately these events are expected to negatively affect fuel consumption.

\section{Econometric Model and Results}

In this paper we employ a dynamic linear fuel consumption specified as follows:

$L X_{i, t}=a_{0}+a_{1} L X_{i, t-1}+$

$\beta_{1} L Y_{i, t}+\beta_{2} L P A S S_{i, t}+\beta_{3} L B U S_{i, t}+\beta_{5} L T R U C K_{i, t}+\beta_{6} L M O T O R_{i, t}+u_{i, t}$

$i=1, \ldots, 51, t=2007, \ldots, 2011$, where $L X$ the logarithm of the per capita consumption of the each kind of fuel (95RON octane, 98-100 RON octane gasoline, LRP and diesel-bio), LY the logarithm of per capita GDP, LPASS the logarithm of per capita number of passenger vehicles, LBUS the logarithm of per capita number of busses, LTRUCK the logarithm of per capita number of trucks and, LMOTOR the logarithm of per capita number of motorcycles.

Model (1) has been estimated using Arellano-Bond (1991) GMM estimation method.

Under formulation (1) the short run income elasticities of fuel consumption are $\beta_{1}$ and the long run ones are $\frac{\beta_{1}}{1-a_{1}}$. 
Estimates of the income elasticities are presented in table 1 (insignificant at $10 \%$ level estimates are in parentheses). The empirical results show that gasoline 95RON is income inelastic both in the short run and the long run. All other fuels are income elastic with diesel-bio fuel elasticity close to unity. Gasoline 98-100RON has the highest income elasticity implying that this type of fuel should have experienced most losses due to income reductions relative to other fuels. Furthermore the sign of the elasticity estimators classifies all fuel-types as normal goods.

Comparing geographic departments' fuel consumption income elasticity, it can be said that Ionian and Aegean Islands present high income elasticity rates for 98-100 RON octane unleaded and super gasoline LRP. Moreover, Ionian Islands' income elasticity for diesel-bio fuel is almost unitary in the short run and a half in the long run. Income elasticities for Crete show similar behavior. Crete's fuel consumption super gasoline shows high income sensitivity (its long run income elasticity value is almost three times higher than that of Ionian and Aegean Islands). Interestingly enough Crete and Aegean Islands exhibit negative short run and long run income elasticities for 95 RON octane unleaded gasoline. This implies that income reduction due to economic crisis in these islands has increased demand for 95 RON octane unleaded gasoline, ceteris paribus.

As far as the mainland Greece concerns, remarkable high are Epirus's income elasticities of 95 RON octane unleaded gasoline, in the short and long run time period

Table 1. Geographic department' income elasticities ( $\mathrm{S}=$ short-run, L=long-run)

\begin{tabular}{rccccc}
\hline & & $\begin{array}{c}98-100 \\
\text { RON } \\
\text { GASOLNE }\end{array}$ & $\begin{array}{c}\text { 95 RON } \\
\text { GASOLNE }\end{array}$ & $\begin{array}{c}\text { NEW SUPER } \\
\text { GASOLINE }\end{array}$ & $\begin{array}{c}\text { DIESEL AND } \\
\text { BIO FUELS }\end{array}$ \\
& S & 2.479 & 0.889 & 2.307 & 1.210 \\
Thrace & S & 2.836 & 0.512 & -3.153 & 1.115 \\
& L & 6.158 & 0.492 & 15.671 & 1.348 \\
Macedonia & S & $(-0.003)$ & 1.058 & $(0.884)$ & 1.339 \\
& L & $(-0.021)$ & 0.804 & $(3.742)$ & 1.496 \\
Epirus & S & $(0.382)$ & 4.062 & 2.751 & $(0.868)$ \\
& L & $(4.600)$ & 3.527 & -4.753 & $(3.496)$ \\
Thessaly & S & 3.031 & $(0.554)$ & $(1.058)$ & $(-0.483)$ \\
& L & 4.182 & & $(2.277)$ & $(-0.635)$ \\
& & & $(0.489)$ & & \\
Central Greece & S & $(3.699)$ & $(0.134)$ & $(1.117)$ & 1.119 \\
& L & 5.486 & $(0.083)$ & $(18.017)$ & $(0.621)$ \\
Peloponnesus & S & 3.856 & $(0.331)$ & 2.094 & $(1.487)$ \\
& L & 3.580 & $(0.216)$ & 2.283 & 0.968 \\
Aegean Islands & S & 5.524 & -3.654 & 2.095 & $(0.384)$ \\
& L & 6.497 & -2.289 & $(5.411)$ & $(0.254)$ \\
\hline
\end{tabular}




\begin{tabular}{rlcccc}
\hline Ionian Islands & $\mathrm{S}$ & 4.582 & $(-0.052)$ & 4.862 & 0.955 \\
& $\mathrm{~L}$ & 4.331 & $(-0.041)$ & 5.203 & 0.596 \\
Crete & $\mathrm{S}$ & $(1.844)$ & -0.794 & 1.061 & $(0.284)$ \\
& $\mathrm{L}$ & 2.932 & -2.705 & 14.491 & 0.538 \\
\hline
\end{tabular}

Thrace, Thessaly, Central Greece and Peloponnesus show high income sort and long run elasticities in 98-100 RON octane unleaded gasoline. For Thrace the 95 RON gasoline consumption is income inelastic whereas the opposite is true for diesel-bio fuel consumption. Furthermore Thrace's value of long income elasticity for gasoline LRP is similar to that of Crete.

Macedonia has unitary income elasticity for 95 RON gasoline consumption in the short run. On the contrary its value in the long run falls below unity.

In conclusion, fuel consumption responses to income changes differ among different geographic regions in Greece. More specifically for the most demanded fuel 95 RON gasoline, consumers in the islands considered this product as inferior whereas the opposite holds true for the consumers in the rest of Greek territory. Concerning diesel-bio fuel consumption the consumers in the islands react more conservatively to income changes than the other Greek consumers. For the other types of fuels i.e. 98-100 RON gasoline and gasoline LRP there are not any noticeable differences in consumers' behavior among the different geographic regions in Greece.

\section{Conclusion}

The implementation of austerity measures, which started being applied in Greece from the February of 2010, had as a result prolonged income declines. Citizens' behavior changed causing an important decrease in fuel consumption.

However, fuel consumers had different behavior compared to different types of fuel and different geographic regions in Greece. New super gasoline LRP and 98-100 RON octane unleaded gasoline are proven to be income elastic without consumers' behavior to differ geographically.

New super gasoline LRP is used by the majority of motorcycles' model before 2002, as well as by old cars and antiques. But the number of vehicles which use the specific fuel reduces year after year. Moreover, in combination with the greater expenditure which is necessary for these vehicles (i.e. higher road tax) it is obvious why this fuel is affected so much by the income shifts (positively) and the number of motorcycles (negatively).

Fuels with high demand as the diesel-bio fuels and 95 RON octane unleaded gasoline seem to be quite less elastic as compared to other types of fuels (98-100 RON and LRP gasoline) in the short and the long run. Moreover consumers' 
behavior in Greek islands differs to that of the rest Greek territory. This empirical finding supports the importance of peculiar geographic factors affecting fuel consumption decisions.

\section{References}

Drettakis, M,. 2011, “2010 country's per capita GDP landslide at the 2005 level” (in Greek). Available at:

http://archive.avgi.gr/ArticleActionshow.action?articleID=616280, (date of last access 12 February 2014).

Heinz, D., 2011, "European debt crisis 2011. Portugal, Ireland, Italy, Greece, Spain and Belgium IAC Society", $138 \mathrm{p}$.

Mah, G. et al, 2013, "The Impact of Government Expenditure on the Greek Government Debt: An Econometric Analysis". Mediterranean Journal of Social Sciences 4 no 3.

Ministry of Environment, Energy and Climate Change, 2011, "Weekly press review of unleaded gasoline's prices" (in Greek). Available at:

http://www.ypeka.gr/LinkClick.aspx?fileticket=IZ3JEUBfatE\%3D\&tabid=478\&langua ge=el-GR, (date of last access 3 February 2014).

Ministry of Regional Development and Competitiveness, 2011, "Nationwide average price of regular unleaded: 1.71 euros per liter - Fixed margins in the internal market." Available at: http://www.mindev.gov.gr/?p=4249, (date of last access 3 February 2014).

Ministry of Regional Development and Competitiveness. 2014. "Price Observatory of Liquid Fuels" (in Greek). Available at:

http://www.fuelprices.gr/price_stats_ng.view?time=1\&prodclass=1, (date of last access 1 February 2014).

The world fact book. Available at: https://www.cia.gov/library/publications/the-worldfactbook/. (date of last access 4 February 2014). 